\title{
Evaluation of Effects of Medical Reconciliation in Renal Failure Patients in a Tertiary Care Hospital
}

\author{
Elna Babu, Hema Palanichamy, Nikhil Vinod*, Shambavi Ravichandar, Rama Parthasarathy \\ Department of Pharmacy Practice, PSG College of Pharmacy, Coimbatore, Tamil Nadu-641004, INDIA.
}

\begin{abstract}
Renal failure is one of the major health problems in the world. Any gaps in the patient care may affect the patient adherence and quality of life. As part of a multi-disciplinary patient care strategy, clinical pharmacy service has led to improvement in patient care. The purpose of the study is to evaluate the role of medication reconciliation in renal failure patients and to observe the effect of medication alert card and patient counseling in medication reconciliation. In control, Drug Related Problems (DRPs) were identified only by chart review. In test group, one arm containing patients with DRPs were identified using medication reconciliation alone and in second arm, patient counseling and medication alert card was used in addition to reconciliation. Patient data were recorded on a standard template obtained from The Manitoba Renal Program (Canada). DRPs were recorded. Knowledge was assessed with a questionnaire before and after counseling and it was quantified. More number of DRPs was identified by means of medication reconciliation. Patient counseling and medication alert card had a significant role in medication reconciliation. The study was statistically significant with $P<0.05$. Medication reconciliation in renal failure helps to identify more number of drug related problems. Patient counseling and medication alert card have effectively improved the effect of reconciliation in renal failure patients and thus could improve clinical outcomes and quality of life.
\end{abstract}

Key words: Medication reconciliation, Patient counselling, Medication alert card, Renal failure.

\section{INTRODUCTION}

Renal failure also known as renal insufficiency is the reduced ability of the Kidney to filter the waste materials mainly, the nitrogenous products. Chronic kidney disease (CKD) and End Stage Renal Disease (ESRD) are emerging public health problems in developing countries thereby needing changes in health-care policy. When patients having intercurrent diseases receive multiple medications, their chances of Drug Related Problems (DRPs) like druginteractions and adverse drug reactions tend to increase. ${ }^{1}$ Drug-related problems include medication errors (involving an error in the process of prescribing, dispensing, or administering a drug, whether there are adverse consequences or not) and adverse drug reactions. ${ }^{2}$ To reduce the burdens of DRPs caused on the patient as well as the health care provider, it is essential to implement methods to identify and measure such DRPs and tools to rectify the same. Some of the tools available are medication reconciliation, patient counselling and medication alert card. Medical reconciliation according to Joint Committee Accreditation Health Care Organizations (JCAHO) is the "process of comparing a patient's medication orders to all of the medications that the patient has been taking". 3 This reconciliation is done to avoid medication errors such as omissions, duplications, dosing errors or drug interactions and Adverse Drug Events (ADEs). ESRD patients on an average are prescribed with 10-12 medications which increases the potential for Drug Related problems (DRPs) including inappropriate dose or indication for a medication and Adverse Drug Events (ADEs). Medication discrepancies are
DOI: 10.5530/ijopp.10.3.36

Address for correspondence: Nikhil Vinod*, Department of Pharmacy Practice, PSG College of Pharmacy, Coimbatore, Tamil Nadu-641004, INDIA.

Phone no: 9003818276 E-mail: nikhilvinod999@gmail. com

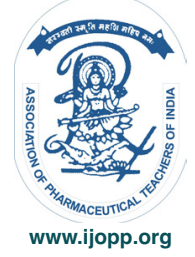


bound to occur unintentionally due to medication use before admission and after discharge. These are points of care where patient is more exposed to medication discrepancies as the responsibilities of a patient are transferred among health professionals. ${ }^{4}$

The significance of medication reconciliation includes mainly assessing whether the desired therapeutic outcomes are being achieved, monitoring for Drug Related Problems (DRPs), monitor for toxicity, ensure rational and quality use of medicines, assess patient's compliance (medication adherence), assess the completeness of medication chart, compare the inhospital and discharge medication and judge whether medicines should be included and omitted or if better alternatives could be suggested. ${ }^{5}$

Components majorly include medication order review (MOR) / Treatment Chart Review (TCR), Clinical review/ Daily Progress Review, detection and management of Adverse Drug Reactions (ADRs). ${ }^{5}$

\section{Steps involved in medication reconciliation process includes the following.}

1. Verification- The current (in-hospital) medication list is assembled by using 1 or more sources of information (e.g.: pharmacy records, general practitioner medical records, medication vials brought by the patient, information provided by the patient and his/her family in patient counselling). ${ }^{6}$

2. Clarification- The medication and dosages are checked for appropriateness. ${ }^{6}$

3. Reconciliation- Newly prescribed medications are compared against the old ones and changes to pharmacotherapy are documented. ${ }^{6}$

4. Transmission-The updated and verified list is communicated with the next provider of care. ${ }^{6}$

Patient counselling refers to the process of providing information, advice and assistance to help patients use their medications appropriately. The information and advice is given by the pharmacist directly to the patient or to the patient's representative and may also include information about the patient's illness and recommended lifestyle changes. The contents of typical counselling include Correct storage, minimum duration required to show therapeutic benefit, what to do if a dose It includes name and strength of the medication, the reason why it has been prescribed (if known), or how it works, how to take the medication? (how much and how often), expected duration of treatment, expected benefits of treatment, possible adverse effects, possible medication or dietary interactions, advice on is missed? special monitoring requirements, for example: blood tests and arrangements for obtaining further supplies. ${ }^{7}$

\section{MATERIALS AND METHODS}

\section{Study design and location}

A prospective interventional study was conducted in the department of nephrology PSG Hospitals, Coimbatore. The study was approved by Institutional Ethics Committee (IHEC, PSG IMS and R) on 29/01/2016.

\section{Study subjects and duration}

All adults discharged with at least one prescribed drug from the department of Nephrology were included. The study was conducted for a period of six months.

\section{Inclusion criteria}

- Above 18 years of age.

- Patient willing to give consent.

- Renal failure and dialysis patients.

\section{Exclusion criteria}

- Pregnancy and lactation

- Psychiatric disturbances

- Death

- Transferred to another ward or hospital

Discharge within $24 \mathrm{~h}$ or out of office $\mathrm{h}$ and patients who could not be counseled (as stated by hospital physician due to physical/mental constraints, language restrictions or terminal illness) in the year $2016 .^{11}$

\section{PROCEDURE}

Medication review and reconciliation was conducted and documented using a standard template from the Manitoba Renal Program (Canada). ${ }^{8}$ Medication alert card and its questionnaire were obtained from Medipal. Patient counseling questionnaire was obtained from World journal of pharmacy and pharmaceutical sciences for assessing the knowledge before and after counselling in renal failure patients. Medication reconciliation intervention chart was obtained from PCNE version-4 used by the physicians to make the interventions with the medication list. ${ }^{10}$

The study contained one test group and control group. A control group was created in which medical reconciliation, 
patient counselling and medication alert card were not provided. In the test group, medication reconciliation was performed. This group was divided into two to determine the effect of patient counselling and medication alert card on medication reconciliation. More number of DRPs was identified by means of medication reconciliation. Student $t$-test was used to compare the Test and the Control. Paired-t-test was used to compare Group-1 and Group-2 under the Test. Patient counseling and medication alert card had significant role in medication reconciliation. The study was statistically significant with $P<0.05$.

\section{RESULTS AND DISCUSSION}

\section{Patient demographics of study patients}

\section{Age wise distribution}

A total of 152 subjects were included in this study. Subjects were classified into 3 age groups less than 40 years, $40-60$ years and greater than 60 years. There were $21.05 \%$ subjects in the age group of less than 40 years, $44.73 \%$ in $40-60$ years and $34.21 \%$ in the age group greater than 60 years. As per the results, maximum subjects $(44.73 \%)$ were in the age group of 40 to 60 years, followed by greater than 60 years (34.21\%). Table 1 .

\section{Gender wise distribution}

Among total population of 152 patients, $65.78 \%(n=100)$ were males and $34.21 \%(\mathrm{n}=52)$ were females. In this group, male subjects were more compared to female subjects Table 2 .

\section{Comorbidities in CKD patients}

In CKD patients, the most common co morbidity identified was Systemic hypertension (44.26\%) followed by diabetes mellitus $(24.50 \%)$, congestive heart failure and sepsis $(5.13 \%)$. Table 3.

\section{Table 1: Frequency Distribution of Age.}

$\begin{array}{ccc}\text { Age group } & \text { No. of subjects }(\mathbf{n}=\mathbf{1 5 2}) & \text { Percentage }(\%) \\ <40 \text { years } & 32 & 21.05 \\ 40-60 \text { years } & 68 & 44.73 \\ >60 \text { years } & 52 & 34.21 \\ \text { Total } & 152 & 100.00\end{array}$

\begin{tabular}{|ccc|}
\hline \multicolumn{3}{c|}{ Table 2: Gender Distribution in CKD Patients. } \\
\hline Gender & No. of subjects(n=152) & Percentage (\%) \\
Male & 100 & 65.78 \\
Female & 52 & 34.21 \\
Total & 152 & 100.00
\end{tabular}

\section{Commonly prescribed drugs}

The table provides data regarding the commonly prescribed drugs in the CKD patients. Among these, the most commonly prescribed drugs are hemantinics $(18.16 \%)$ and vitamin supplements (18.16\%). Table 4.

\begin{tabular}{|ccc|}
\hline \multicolumn{3}{c|}{ Table 3: Comorbidities in CKD Patients. } \\
\hline Comorbidities & No. of patients & Percentage (\%) \\
Systemic hypertension & 112 & 44.26 \\
Diabetes mellitus & 62 & 24.50 \\
Congestive heart failure & 13 & 5.13 \\
Cerebrovascular accident & 7 & 2.76 \\
SLE & 7 & 2.76 \\
IHD & 5 & 1.97 \\
Hypothyroidism & 6 & 2.37 \\
Sepsis & 13 & 5.13 \\
Others & 28 & 11.06 \\
Total & 253 & 100.00
\end{tabular}

\section{Table 4: Commonly Prescribed Drugs.}

\begin{tabular}{|c|c|c|}
\hline Category of drugs & No. of drugs & Percentage (\%) \\
\hline Beta blocker & 33 & 2.22 \\
\hline Alpha blocker & 31 & 2.09 \\
\hline $\mathrm{CCB}$ & 74 & 4.99 \\
\hline$\underline{\alpha}-2$ agonist & 29 & 1.96 \\
\hline ACE I/ARB & 40 & 2.70 \\
\hline Diuretics & 26 & 1.75 \\
\hline Insulin & 39 & 2.63 \\
\hline Hypoglycaemic agents & 3 & 0.20 \\
\hline Vasodilators & 40 & 2.70 \\
\hline Antiplatelet agents & 44 & 2.97 \\
\hline Antibiotics & 88 & 5.94 \\
\hline Antifungal & 2 & 0.13 \\
\hline Inotropic agents & 17 & 1.14 \\
\hline Haematinics & 269 & 18.16 \\
\hline Antithyroid agents & 13 & 0.87 \\
\hline Vitamin & 269 & 18.16 \\
\hline Sodium bicarbonate & 7 & 0.47 \\
\hline Potassium supplements & 3 & 0.20 \\
\hline Calcium & 81 & 5.46 \\
\hline Electrolytes & 18 & 1.21 \\
\hline Phosphate binder & 33 & 2.22 \\
\hline PPI & 119 & 8.03 \\
\hline H2 receptor blocker & 3 & 0.20 \\
\hline Antianginal & 15 & 1.01 \\
\hline Statins & 23 & 1.55 \\
\hline Steroids & 12 & 0.81 \\
\hline Immunosuppressants & 7 & 0.47 \\
\hline Probiotics & 5 & 0.33 \\
\hline Others & 138 & 9.31 \\
\hline Total & 1481 & 100.00 \\
\hline
\end{tabular}




\section{Types of errors identified}

In the control group, 72 total errors were identified. Among these transcribing errors was more $(34.72 \%)$ followed by wrong dose (19.44\%) and administering error $(18.05 \%)$. Table 5. In test group 1, 44 total errors were identified. Among these, omission and administering errors $(27.27 \%)$ were found to be more followed by wrong dose and wrong dosage form errors $(11.36 \%)$.Table 7 . In test group 2, 73 total errors were identified. Among these, administering error (24.65\%) were found to be more, followed by transcribing error $(19.17 \%)$, wrong dose and omission error (15.06\%). Table 9. As per the study conducted by Landon, lack of information on discharge prescriptions about the medication prescribed, re-prescribed without any changes or discontinued during hospital stay was the main source of discrepancies. Findings from our study support the need for the multiple disciplinary practice of discharge and admission medication reconciliation. This process should clarify the status of medication the patient was taking prior to admission and it must also account for all new medications started in hospital, discontinued medications and adjusted medications to their dose.

\section{Interactions identified}

In the control group, total number of interactions identified was 196. Among these, significant interactions were found to be more $(61.22 \%)$, followed by minor $(27.55 \%)$ and serious $(11.22 \%)$. Table 6 . In test group 1 , total number of interactions identified was 69. Among these, significant interactions were found to be more $(53.62 \%)$, followed by minor (39.13\%) and serious (7.24\%) Table 8 . In test group 2, total number of interactions identified was 77. Among the identified interactions, significant interactions were found to be more $(62.33 \%)$, followed by minor $(29.87 \%)$ and serious $(7.79 \%)$ Table 10. According to a study by Varkey et al, which was split into two phases I: with only admission medication review and II: in hospital and discharge medication review, it was found that phase I had $4 \%$ serious, $47.7 \%$ significant and $48.4 \%$ minor drug interaction and it was found that in phase II the percentages of the same were 1.1\%, 20.9\% and $78 \%$ respectively. ${ }^{12}$ As per Raghavan et.al study among 156 patients, 474 drug interactions were identified with 2.7 interactions per patient. Among 474 potential interactions, when classified according to resulting effect, the frequency of outcomes of drug-disease interactions was found that $150(31.65 \%)$ may lead to hypotension or hypertension related to beta blockers and calcium channel blockers, 67 (19.14\%) hypoglycaemia or hyperglycaemia associated insulin, and $25(5.27 \%)$ hyperkalaemia associated with ACEI. This shows that medication reconciliation plays a significant role in identification of drug related problems in hospitalised patients.

\section{Medication reconciliation interventions}

Medication reconciliation is a resource intensive process that targets efforts in ways that maximize impact on patient safety. Some studies show that errors during discharge are more, even though drug related problems didn't occur only due to lack of medication reconciliation but also due to inadequate information about the pharmacotherapy of the patient. ${ }^{4}$ Many studies show that drug use by the patient and what has been recorded

\begin{tabular}{|c|c|c|}
\hline Types of errors & No. of errors & Percentage (\%) \\
\hline Prescribing & 5 & 6.94 \\
\hline Transcribing & 25 & 34.72 \\
\hline Administering & 13 & 18.05 \\
\hline Wrong drug & 3 & 4.16 \\
\hline Wrong strength & 4 & 5.55 \\
\hline Wrong dose & 14 & 19.44 \\
\hline Wrong time & 1 & 1.38 \\
\hline Omission & 4 & 5.55 \\
\hline Wrong dosage form & 3 & 4.16 \\
\hline Total & 72 & 100.00 \\
\hline
\end{tabular}

Table 6: Interactions Identified in the Control Group.

$\begin{array}{ccc}\text { Type of interactions } & \text { No. of errors } & \text { Percentage (\%) } \\ \text { Significant } & 120 & 61.22 \\ \text { Serious } & 22 & 11.22 \\ \text { Minor } & 54 & 27.55 \\ \text { Total } & 196 & 100.0\end{array}$

Table 7: Types of Errors Identified in the Test Group 1.

$\begin{array}{ccc}\text { Types of errors } & \text { No. of errors } & \text { Percentage (\%) } \\ \text { Prescribing } & 3 & 6.81 \\ \text { Transcribing } & 3 & 6.81 \\ \text { Administering } & 12 & 27.27 \\ \text { Wrong drug } & 3 & 6.81 \\ \text { Wrong dose } & 5 & 11.36 \\ \text { Wrong time } & 1 & 2.27 \\ \text { Omission } & 12 & 27.27 \\ \text { Wrong dosage form } & 5 & 11.36 \\ \text { Total } & 44 & 100.00\end{array}$

Table 8: Interactions Identified in the Test Group 1.

$\begin{array}{ccc}\text { Type of interactions } & \text { No. of errors } & \text { Percentage (\%) } \\ \text { Significant } & 37 & 53.62 \\ \text { Serious } & 5 & 7.24 \\ \text { Minor } & 27 & 39.13 \\ \text { Total } & 69 & 100.00\end{array}$




\begin{tabular}{|ccc|}
\hline \multicolumn{3}{|c|}{ Table 9: Types of Errors Identified in the Test Group 2.} \\
\hline Types of errors & No. of errors & Percentage (\%) \\
Prescribing & 6 & 8.21 \\
Transcribing & 14 & 19.17 \\
Administering & 18 & 24.65 \\
Wrong drug & 5 & 6.84 \\
Wrong dose & 11 & 15.06 \\
Wrong time & 1 & 1.36 \\
Omission & 11 & 15.06 \\
Wrong dosage form & 7 & 9.58 \\
Total & 73 & 100.00
\end{tabular}

\section{Table 10: Interactions Identified in the Test Group 2.}

$\begin{array}{ccc}\text { Type of interactions } & \text { No. of errors } & \text { Percentage } \% \\ \text { Significant } & 48 & 62.33 \\ \text { Serious } & 6 & 7.79 \\ \text { Minor } & 23 & 29.87 \\ \text { Total } & 77 & 100.00\end{array}$

in the medication list is completely different Therefore, patient participation in medication reconciliation is very much important That is why in our study we included patient counselling. But some studies showed that the impact of patient counselling towards the reconciliation process is still unclear. In this study, we recorded unintended discrepancies between home medication list and admission medication in the patients admitted to the nephrology unit. Nearly all the patients left the hospital with changes in their medication regimen and didn't receive any written instructions highlighting the changes. An effective system must be implemented to ensure adequate patient education and communication between the providers. From the Annals of Pharmacotherapy, edition 2003 we have adopted PCNE version 4 medication reconciliation chart. ${ }^{6}$

\section{Group 1 vs group 2}

Comparing the two test groups, no significant results

\begin{tabular}{|c|c|c|c|c|c|}
\hline \multirow[t]{2}{*}{ Classification } & \multicolumn{2}{|c|}{ Control } & \multicolumn{3}{|c|}{ Test Group 1} \\
\hline & M & SD & M & SD & $\mathbf{p}$ \\
\hline \multicolumn{6}{|c|}{ Prescription-related interventions: correction of unintended discrepancies } \\
\hline Start & 0.5395 & 0.70125 & 0.6842 & 0.61972 & 0.283 \\
\hline Dosage/schemes & 0.5789 & 0.59471 & 0.6316 & 0.54132 & 0.647 \\
\hline Switch:- & 0.000 & 0.000 & 0.6053 & 0.54720 & $0.000^{* * *}$ \\
\hline Stop:- & 0.2237 & 0.41948 & 0.6316 & 0.63335 & $0.000^{* * *}$ \\
\hline \multicolumn{6}{|c|}{ Prescription-related interventions: optimization of pharmacotherapy } \\
\hline Start:- & 0.0132 & 0.11471 & 0.6316 & 0.48885 & $0.000^{* * *}$ \\
\hline Dosage/schemes & 1.1184 & 0.74775 & 1.0526 & 0.76925 & 0.662 \\
\hline Switch & 0.7105 & 0.64943 & 0.8421 & 0.59395 & 0.297 \\
\hline Stop & 0.000 & 0.000 & 0.4737 & 0.55687 & $0.000^{* * *}$ \\
\hline \multicolumn{6}{|c|}{ Patient medication-handling interventions: improvement of medication use by the patient. } \\
\hline Inappropriate medication use & 0.000 & & 0.9474 & 0.83658 & $0.000^{* * *}$ \\
\hline Answering questions on medications & 0.000 & 0.000 & 0.2895 & 0.56511 & $0.000^{* * *}$ \\
\hline Medication supply & 0.000 & 0.000 & 0.2895 & 0.56511 & $0.000^{* * *}$ \\
\hline
\end{tabular}

$\mathrm{N}=76 \mathrm{Patients}$ per control group. $\mathrm{N}=38$ patients per test group $1, \mathrm{P}<0.05=*, \mathrm{P}<0.01=* *, \mathrm{P}<0.001=* * *, 95 \% \mathrm{Cl}, \mathrm{Calculated}$ by using independent $\mathrm{t}$-test.

were obtained with respect to prescription related interventions on correction of unintended discrepancies. In prescription related intervention for the optimization of pharmacotherapy, highly significant results were recorded in 'dosage/schemes'. With patient medication handling interventions, significant results were found in test group 2 compared to that of test group 1 ( $p=0.000$, $p<0.005)$

\section{Control vs test group}

Prescription related interventions; correction of unintended discrepancies by comparing the control and the test groups significant discrepancies were identified in test 'switch' and 'stop' $p<0.05$. With prescription related intervention; optimization of pharmacotherapy significant discrepancies was identified with 'start' and 'stop' in the test group compared to the control $p=0.001$ $(p<0.05)$. With patient education handling interventions; improvement of medication use by the patient significant difference between the two groups were observed. The patients were adequately provided with appropriate use of medication instructions, medication supply and by 
Table 12: Medication Reconciliation Interventions of Test Groups (Group 1 VS Group 2).

\begin{tabular}{|c|c|c|c|c|c|}
\hline \multirow[t]{2}{*}{ Classification } & \multicolumn{2}{|c|}{ TEST (group 1) } & \multicolumn{2}{|c|}{ TEST (group 2) } & \multirow[b]{2}{*}{ p } \\
\hline & M & SD & M & SD & \\
\hline \multicolumn{6}{|c|}{ Prescription-related interventions: correction of unintended discrepancies } \\
\hline Start & 0.6842 & 0.61973 & 0.6842 & 0.90360 & 0.999 \\
\hline Dosage/schemes & 0.6316 & 0.54132 & 0.5526 & 0.68566 & 0.579 \\
\hline Switch:- & 0.6053 & 0.54720 & 0.7105 & 0.69391 & 0.468 \\
\hline Stop:- & 0.6316 & 0.63335 & 0.4211 & 0.59872 & 0.141 \\
\hline \multicolumn{6}{|c|}{ Prescription-related interventions: optimization of pharmacotherapy } \\
\hline Start:- & 0.6316 & 0.48885 & 0.7895 & 0.77661 & 0.292 \\
\hline Dosage/schemes & 1.0526 & 0.76925 & 1.5789 & 0.79293 & $0.004^{* *}$ \\
\hline Switch & 0.8421 & 0.59395 & 0.9211 & 0.63167 & 0.576 \\
\hline Stop & 0.4737 & 0.55687 & 0.3684 & 0.48885 & 0.384 \\
\hline \multicolumn{6}{|c|}{ Patient medication-handling interventions: improvement of medication use by the patient. } \\
\hline Inappropriate medication use & 0.9474 & 0.8684 & 1.8421 & 1.17465 & $0.000^{* * *}$ \\
\hline Answering questions on medications & 0.8684 & 0.87522 & 2.6053 & 1.22009 & $0.000^{* * *}$ \\
\hline Medication supply & 0.2865 & 0.56511 & 1.9211 & 1.47743 & $0.000^{* * *}$ \\
\hline
\end{tabular}

$\mathrm{N}=38$ Patients per group. $\mathrm{P}<0.05=*, \mathrm{P}<0.01=* *, \mathrm{P}<0.001=* * *, 95 \% \mathrm{Cl}$, Calculated by using independent $\mathrm{t}$-test.

Table 13: Patient Counselling Effect of Test Groups (Group 1 and Group 2).

\section{Classification}

Patient counselling effect

Group 1 (no counselling done)

Patient counselling effect

Group 2
Baseline

SD

1.77324

1.95195

5.0263

10.1842

After counselling

M

SD

5.1579

2.03385

$0.010^{* *}$

2.5240

$0.000^{* * *}$

$\mathrm{N}=38$ Patients per group. $\mathrm{P}<0.01=* *, \mathrm{P}<0.001=* * *, 95 \% \mathrm{Cl}, \mathrm{Cal}$ culated by using paired t-test.

answering all the questions posed by the patients in the test group resulting in significant end results.

\section{Patient counselling effect of test groups}

\section{(Group 1 and Group 2)}

The knowledge of patients was assessed during baseline review and final review of both group 1 and group 2 . Comparing mean knowledge between baseline and final review showed statistically significant $(p<0.05)$. The significance was more in test group 2 when compared to group 1. This change in the significance is highly due to counseling done. Viktil et al. showed that, in hospitalized patients, a mean of 4.4 DRPs per patient were recorded due to patient counseling versus a mean of 2.4 DRPs due to using medication records and participating in multidisciplinary team discussions. ${ }^{13}$ Viktil et al. recorded significantly more interventions after patient counseling in the "need for additional drug" and "therapy discussion" categories, which is consistent with our study. These observations point out the impact
Table 14: Knowledge Assessment Scoring for each question after Patient Counselling- Group 1.

$\begin{array}{ccccc}\text { Questions } & \begin{array}{c}\text { No. of } \\ \text { 'yes' } \\ \text { answer }\end{array} & \text { Percentage } & \begin{array}{c}\text { No. of } \\ \text { 'no' } \\ \text { answer }\end{array} & \text { Percentage } \\ \text { Qs1 } & 30 & 78.94 & 8 & 21.05 \\ \text { Qs2 } & 21 & 55.26 & 17 & 44.73 \\ \text { Qs3 } & 18 & 47.36 & 20 & 52.63 \\ \text { Qs4 } & 8 & 21.05 & 30 & 78.94 \\ \text { Qs5 } & 7 & 18.42 & 31 & 81.57 \\ \text { Qs6 } & 19 & 50.00 & 19 & 50.00 \\ \text { Qs7 } & 21 & 55.26 & 17 & 44.73 \\ \text { Qs8 } & 0 & 0 & 38 & 100.00 \\ \text { Qs9 } & 13 & 34.21 & 25 & 65.78 \\ \text { Qs10 } & 13 & 34.21 & 25 & 65.78 \\ \text { Qs11 } & 0 & 0 & 38 & 100.00 \\ \text { Qs12 } & 31 & 81.57 & 7 & 18.42 \\ \text { Qs13 } & 4 & 10.52 & 34 & 89.47 \\ \text { Qs14 } & 2 & 5.26 & 36 & 94.73 \\ \text { Qs15 } & 22 & 57.89 & 16 & 42.10\end{array}$


Table 15: Knowledge Assessment Scoring for each question after Patient Counselling- Group 2.

$\begin{array}{ccccc}\text { Questions } & \begin{array}{c}\text { No. of } \\ \text { 'yes' } \\ \text { answer }\end{array} & \text { Percentage } & \begin{array}{c}\text { No. of } \\ \text { 'no' } \\ \text { answer }\end{array} & \text { Percentage } \\ \text { Qs1 } & 37 & 97.36 & 1 & 2.63 \\ \text { Qs2 } & 32 & 84.21 & 6 & 15.78 \\ \text { Qs3 } & 21 & 81.57 & 17 & 44.73 \\ \text { Qs4 } & 23 & 60.52 & 15 & 39.47 \\ \text { Qs5 } & 23 & 60.52 & 15 & 39.47 \\ \text { Qs6 } & 34 & 89.47 & 4 & 10.52 \\ \text { Qs7 } & 29 & 76.31 & 9 & 23.68 \\ \text { Qs8 } & 19 & 50.00 & 19 & 50.00 \\ \text { Qs9 } & 26 & 68.42 & 12 & 31.57 \\ \text { Qs10 } & 34 & 89.47 & 4 & 10.52 \\ \text { Qs11 } & 15 & 39.47 & 23 & 60.52 \\ \text { Qs12 } & 34 & 89.47 & 4 & 10.52 \\ \text { Qs13 } & 25 & 65.78 & 13 & 34.21 \\ \text { Qs14 } & 10 & 26.31 & 28 & 73.68 \\ \text { Qs15 } & 35 & 92.10 & 3 & 7.89\end{array}$

\section{Table 16: Knowledge Assessment Questionnaire.}

\section{Qs no Questions}

1 Do you know your medical condition or disorder?

2 Do you know the signs and symptoms of your medical condition, disease or disorder?

3 Do you know the total number of medications in your treatment chart?

$4 \quad$ Do you know which medication is used for what purpose in your medication treatment chart?

$5 \quad$ Do you know the dose of your medicines?

6 Do you know the frequency per day of your medications?

7 Do you know which medications should be taken before or after food?

8 Do you know what to do incase you missed a dose?

9 Do you know the storage conditions of your medicines?

10 Do you know which food to avoid?

11 Do you know what to do in case you take a double dose by mistake?

12 Do you know the route of administration of every medicine in your treatment chart?

13 Do you know the serious side effects of your medicines?

14 Do you know which medicines should not be taken together?

15 Do you know the personal care and preventions regarding your disease?

of patient counseling at regular intervals along with the pharmacotherapy to improve the quality of life in CKD and HD patients.
Table 17: Medication Alert Card Questionnaire Scor-

ing for Each Question-Group 2.

$\begin{array}{ccccc}\text { Questions } & \begin{array}{c}\text { No. of } \\ \text { 'yes' } \\ \text { answer }\end{array} & \text { Percentage } & \begin{array}{c}\text { No. } \\ \text { of 'no' } \\ \text { answer }\end{array} & \text { Percentage } \\ \text { Qs1 } & 0 & 0 & 38 & 100 \\ \text { Qs3 } & 37 & 97.37 & 1 & 2.63 \\ \text { Qs4 } & 12 & 31.58 & 26 & 68.42 \\ \text { Qs5 } & 26 & 68.42 & 12 & 31.58 \\ \text { Qs6 } & 22 & 57.89 & 16 & 42.10 \\ \text { Qs7 } & 33 & 86.84 & 5 & 13.16 \\ \text { Qs8 } & 34 & 89.47 & 4 & 10.53 \\ \text { Qs9 } & 31 & 81.58 & 7 & 18.42 \\ \text { Qs11 } & 5 & 13.16 & 33 & 86.84\end{array}$

\section{Table 18: Medication Alert Card Questionnaire.}

$\begin{array}{cc}\text { Qs no } & \text { Questions } \\ 1 & \text { Have you used a medication alert card before? } \\ 3 & \text { Was this medication alert card cost saving? } \\ 4 & \text { Were additional tests done in spite of the medication } \\ \text { alert card? }\end{array}$

Table 19: Response Regarding Storage of Alert Card.

$\begin{array}{cc}\text { Storage } & \text { Percentage } \\ \text { Home } & 21.05 \\ \text { Work } & 2.63 \\ \text { Purse } & 0 \\ \text { Vehicle } & 15.78 \\ \text { Dialysis note } & 60.52\end{array}$

\section{Medication alert card}

In this study, frequently updated medication alert card was provided to the second arm of the cases to in this check their involvement in reducing the potential errors and thus improving the quality of medical care. Medication alert card were distributed to all the 38 cases and the same were frequently updated. Among the results it was shown that all 38 cases $(100 \%)$ had not used such alert cards any time in the past. 37 cases $(97.37 \%)$ found it to be cost saving as no additional test was needed during outside admissions. 22 cases $(57.89 \%)$ found the emergency number in the card to be effective. 33 cases $(86.84 \%)$ claimed the alert card to be updated frequently 
and 34 cases (89.47\%) claimed its efficacy during refills. 31 cases $(81.58 \%)$ found it to be portable. 23 cases $(60.52 \%)$ stored their card in the dialysis note and 33 cases $(86.84 \%)$ claimed that it was not misplaced in the past.

\section{LIMITATIONS OF THE STUDY}

The study was not focused to see the impact of interventions on patients even though the need was present. Duration of the study was limited to provide appropriate interventions to minimize the DRPs identified due to medication reconciliation. The interventions would have been more accurate if compared with interventions done by other healthcare professionals.

\section{ACKNOWLEDGMENT}

The authors thank PSG College of Pharmacy and PSG Hospitals for providing required facilities to carry out this research. They also thank Dr. Prudence Rodrigues for her guidance and support during the study.

\section{CONFLICT OF INTEREST}

The authors declare no conflict of interest.

\section{ABBREVIATIONS USED}

CKD: Chronic kidney disease, ESRD: End stage renal disease, DRP: drug related problems, JCAHO: Joint committee accreditation health care organization, ADE: Adverse drug events, MOR: Medication order review, TCR: Treatment chart review, ADR: Adverse drug reactions, PCNE: Pharmaceutical care network Europe, HD: Hemodialysis, IHD: Ishemic heart disease, SLE: Systemic lupus erythematosus.

\section{REFERENCES}

1. Dipiro JT, Talbert RL, Yee GC, Matzke GR, Wells BG, Posey LM. Pharmacotherapy:A Pathophysiologic Approach, sixth Edition. 1997.

2. Parthasarathi G, Nyfort-Hansen K, Nahata MC. A textbook of Clinical Pharmacy Practice: Edition 2; Adverse Drug Reactions and Pharmacovigilance. P.104-11.

3. Joint Commission on the Accreditation of Healthcare Organizations. Medication reconciliation handbook. Joint Commission Resources and ASHP, 2006.

4. Sarangarm P, London MS, Snowden SS, Dilworth TJ, Koselke LR, Sanchez CO, et al. Impact of Pharmacist Discharge Medication Therapy Counseling and Disease State Education: Pharmacist Assisting at Routine Medical Discharge. 2012;28(4). (2013;28(4):292-300) DOI: 10.1177/1062860612461169.

5. Parthasarathi G, Nyfort-Hansen K, Nahata MC. A textbook of Clinical Pharmacy Practice. Medication Review. 2004;2:190-2.
6. Wong JD, Bajcar JM, Wong GG. Medication reconciliation at hospital discharge: evaluating discrepancies. Ann Pharmacotherapy. 2008;42(10):1373-9. DOI 10.1345/aph.1L19

7. Parthasarathi G, Nyfort-Hansen K, Nahata MC. A textbook of Clinical Pharmacy Practice. Patient counselling.2004;2:60-7.

8. Manitoba renal program http://www.kidneyhealth.ca/wp/9.

9. Information about medical alert card and its benefits. http://www.medipal.org. uk/medipal-card .

10. Karapinar-Çarkıt F, Borgsteede SD, Zoer J, Smit HJ, Egberts ACG, Bemt PM. Effect of Medication Reconciliation with and Without Patient Counselling on the Number of Pharmaceutical Interventions Among Patients Discharged from the Hospital. Published in The Annals of Pharmacotherapy. 2009;43(6):1001-10.

11. Wong JD, Bajcar JM, Wong GG. Medication reconciliation at hospital discharge: evaluating discrepancies. Ann Pharmacotherapy. 2008;42(10):1373-9. DOI 10.1345/aph.1L19

12. Varkey $\mathrm{P}$, Cunningham J, Bisping $\mathrm{S}$. Improving medication reconciliation in the outpatient setting. Joint Commission J Quality Patient Safety. 2007;33(5):286-92. Medline.

13. Kidney-Dis. Relationship between illness perceptions, treatment adherence and clinical outcomes in patients on maintenance haemodialysis. Medication Adherence Behaviour and Priorities Among Older Adults With CKD: A Semi Structured Interview. 2011, Published online. 2010;56(3)43946. doi:10.1053/j.ajkd.2010.04.021PMCID: PMC2935303.NIHMSID: NIHMS217465

14. Anupama YJ, Uma G. Prevalence of CKD among adults in rural community in South India: Results from Kidney Disease Screening. (KIDs) project. Indian Journal of Nephrology. 2014;24(4):214-21.

15. Chae SY, Chae MH, Isaacson N, James TS. The Patient Medication List. Can We Get Patients More Involved in Their Medical Care? Journal of the American Board of Family Medicine. 2009;22(6):677-82. http://www.jabfm. org .

16. Sharma S, Rani RHS, Subramanyam G, Mahvash-Iram. Evaluation of Impact of Counseling on Quality of Life of Chronic Kidney Disease and Haemodialysis Patients. Indian Journal of Pharmacy Practice. 2013;6(3).

17. Varkey P, Cunnigham J, O'Meara J, Bonacci R, Desai N, Sheeler R. Multidisciplinary approach to inpatient medication reconciliation in an academic setting. American Journal of Health-System Pharmacies. 2007;64(8):850-4

18. Rifkin DE, Laws MB, Wilson IB . Relationship between illness perceptions, treatment adherence and clinical outcomes in patients on maintenance haemodialysis. Medication Adherence Behaviour and Priorities Among Older Adults With CKD: A Semi Structured Interview Study. Available in PMC 2011, Published online. 2010;56(3)439-46.

19. Foss S, Schmidt JR, Andersen T. Congruence on medication between patients and physicians involved in patient course. Euro $\mathrm{J}$ Clinical Pharmacology. 2004;59(11):841-7. DOI 10.1007/s00228-003-0708-x

20. Finkelstein FO, Story K. Perceived knowledge among patients cared for by nephrologists about Chronic kidney disease and end stage renal disease therapies. 2008;74(9):1178-84.

21. Stemerand G, Lemmens-Gruber R. Clinical pharmacy activities in chronic kidney disease and end-stage renal disease patients. A systematic literature reviews. Bio Med Central Nephrology. 2011;12(1):35.

22. Kathleen-Tschantz U, MD, MHA, Trista-Pfeiffenberger, MS, Pharm D, et al. Inpatient Medication Reconciliation at Admission and Discharge: A Retrospective Cohort Study of Age and Other Risk Factors for Medication Discrepancies. Published in final edited form as. Am J Geriatric Pharmacotherapy. 2010;8(2):115-26. doi: 10.1016/j.amjopharm.2010.04.002. PMCID: PMC3740385. NIHMSID: NIHMS490180.

23. Prim Care Community Health. 2014;5(1):14-8. doi: 10.1177/2150131913502489. Epub 2013.

24. Makaryus AN, Friedman EA. Patients' understanding of their treatment plans and diagnosis at discharge. Mayo Clinic Proc. 2005;80(8):991- 4.

25. Seema S, Shobha RRH, Geeta S, Mahvashlram: Evaluation of Impact of Counseling on Quality of Life of Chronic Kidney Disease and Haemodialysis Patients. Indian Journal of Pharmacy Practice. 2013:6(3).

26. Coleman EA, Smith JD, Raha D, Min SJ. Posthospital medication discrepancies: prevalence and contributing factors. Arch Intern Med. 2005;165(16):1842-7. DOI 10.1001/archinte.165.16.1842. 